\title{
Mental Health, Mother-Child Interaction and Development at the End of the First Year of Life ${ }^{1}$
}

\author{
Débora Gerardo Ribeiro ${ }^{2}$ \\ Universidade Estadual Paulista "Júlio \\ de Mesquita Filho”, Botucatu-SP, Brazil
}

\author{
Gimol Benzaquen Perosa \\ Universidade Estadual Paulista "Júlio \\ de Mesquita Filho”, Botucatu-SP, Brazil
}

\author{
Flávia Helena Pereira Padovani \\ Universidade Estadual Paulista "Júlio \\ de Mesquita Filho”, Botucatu-SP, Brazil
}

\begin{abstract}
Maternal mental health can affect the quality of the mother-child interaction and, consequently, the development of the child. This study aimed to evaluate the relationship between the mother-child interaction and the neuro-psychomotor development of children at one year of age, taking into consideration the maternal mental health. A total of 65 children, who were registered in Family Health Units, participated, along with their mothers, who responded to a screening interview for common mental disorders. Development was evaluated through a risk screening test. The interaction was assessed through the Dyadic Interaction Assessment Protocol. Developmental risk was presented by $43.1 \%$ of the children. Although $44.6 \%$ of the mothers presented scores indicative of psychological distress, maternal mental health was not associated with the interactive behaviors. Some maternal and child behaviors were associated with developmental delays, however, only cognitive stimulation was shown to be a predictor of delays. The data contribute to the comprehension of the role of the interaction in child development.
\end{abstract}

Keywords: child development, mother-child relationships, risk factors, mental health

\section{Saúde Mental, Interação Mãe-Criança e Desenvolvimento ao Final do Primeiro Ano de Vida}

\begin{abstract}
Resumo: A saúde mental materna pode afetar a qualidade da interação mãe-criança e, consequentemente, o desenvolvimento infantil. Este estudo teve como objetivo avaliar a relação entre interação mãe-filho e o desenvolvimento neuropsicomotor de crianças com um ano de vida, levando em consideração a saúde mental materna. Participaram 65 crianças, usuárias de Unidades de Saúde da Família, e suas mães que responderam a uma entrevista de rastreio para transtorno mental comum. Avaliou-se o desenvolvimento por meio de um teste para rastreamento de risco. A interação foi avaliada pelo Protocolo de Avaliação de Interação Diádica. Apresentaram risco desenvolvimental 43,1\% das crianças. Apesar de 44,6\% das mães pontuarem para sofrimento psíquico, a saúde mental materna não se associou aos comportamentos interativos. Alguns comportamentos maternos e infantis associaram-se a atrasos desenvolvimentais, mas apenas a estimulação cognitiva mostrou-se preditora de atrasos. Os dados contribuem para compreensão do papel da interação no desenvolvimento infantil.
\end{abstract}

Palavras-chave: desenvolvimento infantil, relações mãe-criança, fatores de risco, saúde mental

\section{Salud Mental, Interacción Madre-Hijo y Desarrollo al Final del Primer Año de Vida}

\begin{abstract}
Resumen: La salud mental materna puede afectar la calidad de la interacción madre-hijo y el desarrollo infantil. Este estudio evaluó la relación entre interacción madre-hijo y el desarrollo neuropsicomotor de niños con edad de un año, considerando la salud mental materna. Fueron evaluados 65 niños de un año, usuarios de Unidades de Salud de la Familia, mediante una prueba de detección del riesgo. Las madres fueron entrevistadas y respondieron a instrumento de rastreo psiquiátrico. Se evaluó la interacción mediante un protocolo de interacción diádica. 43,1\% de los niños presentó riesgo de desarrollo. Aunque 44,6\% de las madres presentó malestar psicológico, su salud mental no se asoció con los comportamientos presentados en la interacción. Sin embargo, comportamientos interactivos de la madre y del niño se asociaron con retraso en el desarrollo. La estimulación cognitiva fue la única variable predictiva de retrasos. Los datos contribuyen para la comprensión del papel de la interacción y el desarrollo infantil.
\end{abstract}

Palabras clave: desarrollo infantil, relaciones madre-niño, factores de riesgo, salud mental

One of the priorities of the current Brazilian health model is the surveillance of child development, in order to detect problems in the evolutive process, aiming to alleviate and neutralize the effects of both biological and psychosocial adversity (Amorim et al., 2009; Ribeiro, Silva, \& Puccini, 2010; Santa Maria-Mengel \& Linhares, 2007). The behavior

\footnotetext{
Support: Coordination for the Improvement of Higher Education Personnel (CAPES).

2 Correspondence address:

Débora Gerardo Ribeiro. Avenida Bandeirantes, 55, Centro. CEP 86360000. Bandeirantes-PR, Brazil. E-mail: deboragerardo@gmail.com
}

of the caregiver (mother) has a decisive role in the protection and development of children exposed to risk in the family context, such as low socioeconomic status, low levels of education, chronic illnesses, death, conflict, violence, and mental health problems of the caregiver (Engle, 2009, Parsons, Young, Rochat, Kringelbachach, \& Stein, 2012). Good parent-child communication and the quality of early interactions, especially maternal sensitivity, have been identified as variables that play a protective role in the development of the child (Pinheiro, 2004; Shin, Park, Ryu, \& Seonum, 2008) especially with regard to socioemotional, language and cognition development (Field, 2010; L. 
Murray, Halligan, \& Cooper, 2010; Stein, Malmberg, Sylva, Barnes, \& Leach, 2008).

According to Feldman and Klein (2003), to assess the quality of the interaction, the majority of studies use recordings of episodes of free interaction between the mother and the child, analyzed by two types of codes. The first, microanalytical, includes the recording, over short intervals of time, of a series of discrete behaviors, such as what the child looks at, vocalizes, touches, and facial expressions, which allows a quantitative description of the categories selected for the analysis of the episode. Alternatively, following the tradition of Ainsworth, researchers have used global assessment scales when evaluating interactive characteristics in the episode as a whole, the responsiveness, intrusiveness and reciprocity, from psychometric Likert type scales.

Studies has shown that, among the factors associated with the quality of the interaction, maternal mental health, particularly chronic depression (Frizzo \& Piccinini, 2007; Lovejoy, Graczyk, O’Hare, \& Neuman, 2000; L. Murray et al., 2010) or extreme anxiety (Glasheen, Richardson, \& Fabio, 2010), may adversely affect the mother-child interaction and child development, and that its effects can be maintained for a long period. The risks increase when it comes to depressed mothers who live in vulnerable environments, with unfavorable economic conditions, and little social support (Parsons et al., 2012; Stein et al., 2008).

It is hypothesized that mothers, especially those who are depressed, who are not emotionally available for the child have a more apathetic style of interacting, tend to be less responsive, and offer few facilitating behaviors for the exploration of objects, which may lead to psychosocial deprivation and adverse development conditions (L. Murray et al., 2010; Tran et al., 2014). According to Lovejoy et al. (2000) in a review article, these difficulties are not specific to mothers diagnosed with depression, but may appear in mothers with subclinical levels of depression or even accompany other psychiatric disorders.

There are studies associating the quality of the interaction and child development with the depressive or anxious symptoms of the mother, however, very little is known about the role of the so-called common mental disorders (CMDs) in the quality of the mother-child interaction. These conditions are of high prevalence in the adult population, especially among women with low socioeconomic status (Lima et al, 2008; Maragno, Goldbaum, Gianini, Novaes, \& César, 2006), and are characterized by multiple symptoms, such as nonspecific somatic complaints, irritability, insomnia, nervousness, headaches, fatigue, forgetfulness, and lack of concentration, as well as various events that, while not necessarily meeting all the diagnostic criteria for mental illness according to the ratings of the DSM-V and ICD -10, could be characterized as depressive, anxious or somatoform symptoms.

Another aspect rarely mentioned in the literature is related to the role of the child in the interaction. Although the interaction is characterized as a reciprocal and bidirectional action and there is strong evidence that, from the start of development, it is not only determined by the actions of the mother (Klein \& Linhares, 2006; Lopes et al., 2012; Seidlde-Moura et al., 2008), studies of the interaction of mothers with very young children are focused on the maternal behaviors, and on the ways the adult alters her behavior and the surrounding physical environment to accommodate the demands and limitations of the child (Lordelo, Fonseca, \& Araújo, 2000; Lyra, Silva \& Silva, 2012). According to Lordelo et al. (2000), in a phase in which the child still has a limited motor repertoire and little communicative ability, it is necessary to delegate more responsibility to the adult and consider that the maternal role is a critical variable in the interactive process, which does not absolve the researcher from observing the role of child in the interaction or from acknowledging the possible participation of the child.

Based on the above, this study aimed to evaluate the relationship between the mother-child interaction and the neuropsychomotor development of children at one year of age, taking into consideration the maternal mental health. The intention was, therefore, to identify the role that maternal mental health plays in the interaction, especially regarding the common mental disorders, as well as the role of the child in the interaction. The following hypotheses were constructed: (a) in the dyadic interaction, mothers without common mental disorders emit more qualitatively positive behaviors (sensitivity, cognitive stimulation, positive affectivity) and less qualitatively negative behaviors (disengagement, coercion, and negative affectivity) than mothers that score positive for CMDs; (b) certain behaviors of the child are associated with certain behaviors of the mother; and (c) disengagement, intrusiveness, insensitivity, and poor maternal cognitive stimulation, as well as less involvement of the child in the interaction, would be configured as risk factors for the neuro-psychomotor development of the child.

\section{Method}

Cross-sectional study, conducted with children and their mothers, living in the catchment area of two family health strategy (FHS) units located in the peripheral areas of a medium-sized city in the state of Sao Paulo.

\section{Participants}

The dyads were selected from consulting the worksheets of the Community Health Agents (CHAs) of the Family Health Unit. All who met the following inclusion criterion were invited to take part in the study: child's age from 11 months and 20 days to 12 months and 20 days. Children with a biological risk mentioned by the mother in the interview, such as mental, motor, or sensory retardation, prematurity, severe neonatal complications, or a long period of hospitalization after birth were excluded. Of 129 dyads who met the inclusion and exclusion criteria, $20.9 \%$ moved to a different catchment area, and $29.4 \%$ refused to participate. The final sample consisted of 65 dyads, users of two FHS units. 


\section{Instruments}

The Dyadic Interaction Assessment Protocol (Piccinini, Frizzo, \& Marin, 2007) was prepared by the Núcleo de Infância e Família of GIDEP/UFRGS (Nudif), based on previous instruments by Cox and Ainsworth (Piccinini et al., 2007). The dyad is asked to play, as they do in everyday life. They are offered toys appropriate for the age and the aim is to evaluate the behavior of the child aged one year and its mother, in a moment of interaction of approximately seven minutes, as suggested by the evaluation instrument.

To evaluate the behavior of the caregiver six categories are used: sensitivity, cognitive stimulation, positive affectivity, negative affectivity, disengagement and intrusiveness. The following four categories are used to evaluate the behavior of the child: involvement, interaction, positive affectivity, negative affectivity. Each category has an average five subcategories.

To evaluate the degree to which the behaviors listed in the instrument were characteristic of the interaction observed in each episode, a model similar to a Likert scale was used, with five measurement points with weightings varying from 1 point for behaviors uncharacteristic of the interaction, up to 5 points for behaviors very characteristic of the interaction. The scores of all the subcategories of each category are added, providing a final score per category that can vary according to the number of subcategories.

Denver Developmental Screening Test II (Frankenburg \& Dodds, 1967, translated and adapted by Pedromônico, Bragatto, \& Strobiluis, 1999). Consists of a screening test for the monitoring of risk and evaluates the development of children, from one month to six years of age, in four general functions: Personal-Social, Language, Fine motor skills and Gross motor skills. The items are evaluated by the applier directly with the child and, in some cases, maternal information is requested.

For the final evaluation, an item is interpreted as "Caution" when the child fails or refuses to perform a task in which between $75-90 \%$ of the comparison sample present such behavior (indicated in the register) and "delayed" when the child fails or refuses to perform a task in which more than $90 \%$ of the children of the same age already present such behavior. The final interpretation of the test presents the indicators: Normal, when there is no "delay" items and, at the most, one "caution" item; Risk when there are two or more "caution" items and/or one or more "delay" items. The Denver II test has good validity and reliability (.99 interobserver and .90 test-retest). It is an easy to perform test and can be applied by various healthcare professionals (Silva et al., 2011).

Self Report Questionnaire-20 - SRQ-20. Developed by Harding et al. (1980) and validated in Brazil by Mari and Williams (1986). This is a questionnaire to screen for psychiatric disorders at the primary health care level. It is composed of 20 questions with dichotomous responses (yes or no), classified in groups of physical symptoms and psycho-emotional disorders (decreased energy, depressed mood and depressive thinking), for the detection of neurotic based common mental disorders. To determine the possibility of a common mental disorder, the cutoff score is eight. Its psychometric qualities are considered adequate: sensitivity between $63 \%$ and $90 \%$ and specificity between $44 \%$ and $95 \%$, with it having been validated in Brazil. The internal consistency index, in the Brazilian version, was 0.86 (Gonçalves, Stein, \& Kapczinski, 2008).

Interview for the Identification of Risk and Biopsychosocial Resources in the Life History of the Child. The script, based on the work of Santa Maria-Mengel and Linhares (2007), was used to characterize the sample in relation to socioeconomic level, environmental/social conditions, pregnancy and child birth conditions, and childcare.

\section{Procedure}

Data collection. After selection of the dyads, the mothers were invited to participate and, if they accepted, they signed the Terms of Free Prior and Informed Consent. In a room that offered them privacy, within the unit itself, the researcher individually applied the Self Report Questionnaire-20 and the Interview Script for the Identification of Risk and Biopsychosocial Resources in the Life History of the Child with the child present. In the same place, in a second step, the neuro-psychomotor development of the child was evaluated by the researcher, using the Denver II test.

In a third step, the dyad was sent to a room of the health unit, containing a table, two chairs and a free space so that the mother and child could move about, and the recording of the episode for free play was initiated. Each interactive episode lasted for approximately seven minutes. The evaluation of the dyadic interaction was videotaped. All the instruments were applied in a single session lasting approximately 60 minutes.

Data analysis. The Denver Screening Test and Self Report Questionnaire-20 were scored and analyzed according to their respective standards. The interactive episodes of the dyad were analyzed as a whole, according to the proposal of the authors, by two independent observers. Of the total observations, $20 \%$ were drawn and evaluated using the Kendall index (SPSS, 1997) for each category of parental and child behavior. As the index was greater than. 80 for the majority of the categories, except positive affectivity of the child and disengagement of the mother, it was considered that there was good concordance between the observers. After establishing all the indices of concordance, the principal researcher analyzed the other videos, in full, attributing the final score.

At first, a descriptive analysis was carried out based on the calculation of frequency, percentage or median, according to the nature of the data. For the analysis of the interactive character between the behaviors of the mother and the behaviors of the child the Spearman correlation test was used. Next, inferential statistical analysis was performed: the Mann-Whitney test was used to compare differences between two independent groups and the Kruskal-Wallis test 
to compare differences between more than two independent groups. The interactive behaviors of the mother and child that presented statistically significant differences between children with normal overall development and those with developmental risk were included in multivariate logistic regression model, aiming to identify the best predictive model for child development. The results were discussed at the $5 \%$ level of significance.

\section{Ethical Considerations}

The study received approval from the Research Ethics Committee of the Faculdade de Medicina de Botucatu - UNESP (Protocol No. 2709/08), as well as from the Municipal Health Secretariat of the municipality and from those responsible for the respective Family Health units. The mothers with mental health problems were referred for care in the health unit itself, and the children referred to the child development outpatient clinic of the Faculdade de Medicina de Botucatu - UNESP.

\section{Results}

Of the 65 children studied, $50.7 \%$ were female. All were born full term, with $80.0 \%$ being via normal birth. A total of $89.2 \%$ were breastfed and the median duration of weaning was 8.5 months. According to the maternal reports, the majority of the children slept normally and feed well, however, $66.1 \%$ were described as "nervous", "agitated" or "obstinate". A third of the mothers reported difficulties in caring for their children, mainly due to being occupied with the household chores. Despite this, the majority (86\%) of the mothers reported that had support in caring for the child.

The majority of the parents were young adults, aged between 20 and 30 years, and more than half had eight or more years of study. The majority of the mothers were housewives $(80.0 \%)$ and $95.3 \%$ of the fathers were employed, of which $36.9 \%$ had skilled occupations. A total of $87.0 \%$ of the families lived in consensual unions. The median family income in minimum wages was 1.64 (Min. $=0.21 ;$ Max. $=4.3$ minimum wages).
In relation to the evaluation of the development, $43.1 \%$ of the children presented overall developmental risk, with the language (24.6\%) and fine motor skills (20.0\%) areas the most affected. A small percentage of the children (6.1\%) presented delay in the personal-social domain, while the gross motor skills area showed $100 \%$ normality. Regarding mental health, $44.6 \%$ of the mothers presented scores indicative of common mental disorders.

Considering the interactive behaviors, there were high scores in sensitivity $(M d n=24$; $\operatorname{Max}=35$; and $\operatorname{Min}=06)$, cognitive stimulation $(M d n=17 ; \operatorname{Max}=35$; and $\operatorname{Min}=7)$, maternal positive affectivity $(M d n=15 ; \operatorname{Max}=29 ;$ and $\operatorname{Min}=8)$ and involvement of the child ( $M d n=16$; $\operatorname{Max}=20$; and Min=5). The indices of negative affectivity, maternal disengagement and intrusiveness, and child negative affectivity were low with medians ranging between 5.0 and 7.0.

No statistically significant differences were observed with respect to the behaviors of mother and child in the interaction of dyads whose mothers scored for common mental disorder and those who did not. As indicated in Table 1, there were statistically significant correlations between the behaviors of the mother and of the child in the interactive situation. The sensitivity, cognitive stimulation and maternal positive affectivity categories were positively correlated with involvement, interaction and positive affectivity and inversely correlated with negative affectivity of the child. Maternal disengagement was negatively correlated with involvement, interaction and positive affectivity of the child and positively with negative affectivity of the child. The negative affectivity and maternal intrusiveness also showed significant correlations with negative affectivity of the child.

Comparing the medians of the interactive behaviors of the children that presented normal development and those at risk, it was found that the mothers whose children had developmental risk presented higher medians in the disengagement and intrusiveness variables. Conversely, the mothers of children with normal development presented a higher median in the cognitive stimulation variable that the mothers of children at risk. The children with normal development also presented a higher median in the involvement variable than the children at risk (Table 2).

Table 1

Correlation Between Maternal and Child Behaviors During the Dyadic Interaction

\begin{tabular}{|c|c|c|c|c|c|c|c|}
\hline \multirow[b]{2}{*}{ Child Behaviors } & & \multicolumn{6}{|c|}{ Maternal Behaviors } \\
\hline & & Sensitivity & $\begin{array}{c}\text { Cognitive } \\
\text { Stimulation }\end{array}$ & $\begin{array}{c}\text { Positive } \\
\text { Affectivity }\end{array}$ & $\begin{array}{l}\text { Negative } \\
\text { Affectivity }\end{array}$ & Disengagement & Intrusiveness \\
\hline \multirow[t]{2}{*}{ Involvement } & rho $^{\mathrm{a}}$ & .65 & .70 & .49 & -.10 & -.66 & -.05 \\
\hline & $p$ & .001 & .000 & .000 & .407 & .000 & .721 \\
\hline \multirow[t]{2}{*}{ Interaction } & rho & .39 & .40 & .32 & -.04 & -.50 & -.19 \\
\hline & $p$ & .001 & .001 & .009 & .778 & .000 & .129 \\
\hline \multirow[t]{2}{*}{ Positive Affectivity } & rho & .36 & .30 & .37 & -.12 & -.42 & -.01 \\
\hline & $p$ & .003 & .015 & .002 & .350 & .001 & .927 \\
\hline \multirow[t]{2}{*}{ Negative Affectivity } & rho & -.52 & -.26 & -.39 & .46 & .34 & .27 \\
\hline & $p$ & .001 & .03 & .001 & .000 & .006 & .029 \\
\hline
\end{tabular}



$p \leq .05$ 
Ribeiro, D. G., Perosa, G. B., \& Padovani, F. H. P. (2014). Mother-Child Interaction and Development.

Table 2

Comparison of Maternal and Child Behaviors During the Dyadic Interaction in Children That Presented (or Not) Overall Developmental Delays

\begin{tabular}{|c|c|c|c|c|}
\hline \multicolumn{2}{|c|}{ Behaviors in the Interaction } & \multicolumn{2}{|c|}{ Denver } & \multirow[b]{2}{*}{$p^{\mathrm{d}}$} \\
\hline Category & Maximum Possible Score & $\begin{array}{c}\text { Normal } \\
M d n^{\mathrm{a}}\left(\min ^{\mathrm{b}}-\mathrm{max}^{\mathrm{c}}\right)\end{array}$ & $\begin{array}{c}\text { Risk } \\
M d n(\text { min-max }) \\
\end{array}$ & \\
\hline Sensitivity & 35 & $26.0(6.00-35.0)$ & $23.0(11.0-35.0)$ & .36 \\
\hline Cognitive Stimulation & 35 & $20.0(8.00-35.0)$ & $12.5(7.00-34.0)$ & .001 \\
\hline Positive Affectivity/Mother & 25 & $17.0(8.00-29.0)$ & $14.0(8.00-22.0)$ & .23 \\
\hline Negative Affectivity/Mother & 25 & $5.00(5.00-19.0)$ & $5.00(5.00-8.00)$ & .10 \\
\hline Disengagement & 20 & $4.00(4.00-18.0)$ & $8.5(4.00-19.0)$ & .01 \\
\hline Intrusiveness & 25 & $5.00(5.00-15.0)$ & $6.00(5.00-24.0)$ & .03 \\
\hline Involvement/Child & 20 & $18.0(8.00-20.0)$ & $13.5(5.00-20.0)$ & .01 \\
\hline Interaction & 25 & $12.0(5.00-17.0)$ & $10.5(10.0-17.0)$ & .41 \\
\hline Positive Affectivity/Child & 20 & $10.0(2.00-18.0)$ & $9.5(4.00-20.0)$ & .55 \\
\hline Negative Affectivity/Child & 25 & $5.00(5.00-19.0)$ & $5.00(5.00-15.0)$ & .78 \\
\hline
\end{tabular}

Note. ${ }^{\mathrm{a}}$ Median; ${ }^{\mathrm{b}}$ Minimum value; ${ }^{\mathrm{c}}$ Maximum value; ${ }^{\mathrm{d}}$ Mann-Whitney. $p \leq .05$

Statistically significant differences in maternal behaviors were observed between the different groups regarding the risk in two subareas of the development: language, and fine motor skills. The group of mothers whose children presented delay or caution profiles in language development presented a lower median in cognitive stimulation and a higher median in disengagement. With respect to the fine motor skills subarea, the mothers whose children presented delay or caution in this had lower medians in sensitivity and cognitive stimulation and higher medians in disengagement and intrusiveness, when compared to the mothers of children with normal development (Table 3).

The interactive behaviors that presented significant differences between the children with normal overall development and those at risk, i.e., involvement, cognitive stimulation, disengagement and intrusiveness, as described in Table 2, were included in the multivariate logistic regression model. Only cognitive stimulation remained as a risk factor for overall development $(\mathrm{OR}=3.83 ; 95 \% \mathrm{CI}=.82$ to .98$)$ that is, children who had mothers that provided less cognitive stimulation were 3.83 times more likely to have a developmental delay.

\section{Discussion}

Qualitatively positive interactive behaviors (Klein \& Linhares, 2006) predominated in the episodes, such as sensitivity, cognitive stimulation, positive affectivity, with low intrusiveness and disengagement on behalf of the mother and little negative affectivity on behalf of both. Confirming the initial hypothesis, positive correlations were observed between the behaviors of the mother and child, suggesting

Table 3

Comparison of Maternal and Child Behaviors During the Dyadic Interaction, in Children That Presented (or Not) Developmental Delays in the Personal/Social, Language, and Fine Motor Skills Areas

\begin{tabular}{|c|c|c|c|c|c|c|c|}
\hline \multicolumn{2}{|c|}{ Denver II } & \multirow{2}{*}{$\begin{array}{l}\text { Sensitivity } \\
M d n^{\mathrm{a}} \\
\left(\min ^{\mathrm{b}}-\max ^{\mathrm{c}}\right)\end{array}$} & \multirow{2}{*}{$\begin{array}{c}\text { Cognitive } \\
\text { Stimulation } \\
M d n \\
\text { (min-max) }\end{array}$} & \multirow{2}{*}{$\begin{array}{l}\text { Positive } \\
\text { Affectivity } \\
M d n \\
\text { (min-max) }\end{array}$} & \multirow{2}{*}{$\begin{array}{l}\text { Negative } \\
\text { Affectivity } \\
M d n \\
\text { (min-max) }\end{array}$} & \multirow{2}{*}{$\begin{array}{c}\text { Disengagement } \\
M d n \\
\text { (min-max) }\end{array}$} & \multirow{2}{*}{$\begin{array}{c}\text { Intrusiveness } \\
M d n \\
\text { (min-max) }\end{array}$} \\
\hline Categories & Level & & & & & & \\
\hline \multirow[t]{4}{*}{$\begin{array}{l}\text { Personal/ } \\
\text { Social }\end{array}$} & Normal & $25.5(7.0-35.0)$ & $20.0(7.0-34.0)$ & $16.0(8.0-29.0)$ & $5.00(5.00-19.0)$ & $6.00(4.00-9.00)$ & $6.50(5.00-8.00)$ \\
\hline & Suspect & $21.0(6.0-35.0)$ & $14.0(7.0-35.0)$ & $15.0(8.0-21.0)$ & $5.00(5.00-9.00)$ & $7.00(4.00-18.0)$ & $8.00(5.00-22.0)$ \\
\hline & Delay & $27.5(24.0-34.0)$ & $15.0(13.0-34.0)$ & $18.5(14.0-22.0)$ & $5.00(5.00-5.00)$ & $6.00(4.00-19.0)$ & $6.00(5.00-24.0)$ \\
\hline & $p^{1}$ & .12 & .28 & .43 & .54 & .52 & .54 \\
\hline \multirow[t]{4}{*}{ Language } & Normal & $24.0(11.0-35.0)$ & $21.5(13.0-34.0)$ & $17.0(8.00-29.0)$ & $5.00(5.00-8.00)$ & $4.50(4.00-18.0)$ & $5.00(5.00-14.0)$ \\
\hline & Suspect & $24.0(15.0-34.0)$ & $17.0(7.00-35.0)$ & $18.5(12.0-32.0)$ & $5.00(5.00-8.00)$ & $6.50(4.00-9.00)$ & $8.00(5.00-18.0)$ \\
\hline & Delay & $25.0(6.00-35.0)$ & $12.0(7.00-33.0)$ & $11.0(8.00-20.0)$ & $5.00(5.00-19.0)$ & $10.0(4.00-19.0)$ & $6.00(5.00-24.0)$ \\
\hline & $p^{1}$ & .07 & .01 & .08 & .422 & .05 & .10 \\
\hline \multirow[t]{3}{*}{$\begin{array}{l}\text { Fine Motor } \\
\text { Skills }\end{array}$} & Normal & $25.5(6.00-35.0)$ & $19.5(7.00-35.0)$ & $17.0(8.00-29.0)$ & $5.00(5.00-8.00)$ & $6.0(4.00-19.00)$ & $5.00(5.00-11.0)$ \\
\hline & Delay & $17.0(11.0-31.0)$ & $11.0(7.00-27.0)$ & $14.0(9.00-21.0)$ & $5.00(5.00-19.00)$ & $9.00(4.00-13.0)$ & $6.00(5.00-24.0)$ \\
\hline & $p^{2}$ & .04 & .004 & .12 & .40 & .05 & .05 \\
\hline
\end{tabular}

Note. ${ }^{\mathrm{a}}$ Median; ${ }^{\mathrm{b}}$ Minimum value; ${ }^{\mathrm{c}}$ Maximum value; $p^{1}$ Kruskal Wallis; $p^{2}$ Mann-Whitney. $p \leq .05$ 
reciprocal relationships of mutuality present in the early social development (Klein \& Linhares, 2006; Seidl-de-Moura et al., 2008). The children more involved in the interaction, who demonstrated affectivity in a positive way, with smiles, enthusiasm, physical demonstrations of affectivity and few episodes of negative affectivity had mothers who were more sensitive, stimulating and positively affective. In contrast, the mothers that were more unengaged had children that interacted less and were less involved and that presented fewer positive and more negative affective behaviors.

The prevalence of symptomatology for common mental disorders, in this sample, was higher than in other Brazilian studies (Lima et al., 2008; Maragno et al., 2006), possibly because the sample was composed exclusively by women, living in poor areas. Lima et al. (2008) and Maragno et al. (2006) found a significant association between CMDs and social disadvantage and the female gender. Having young children who are beginning to become independent has also been implicated as a risk factor for mental disorders due to creating additional challenges for the parents, requiring protection and demanding care (Araújo, Pinho, \& Almeida, 2005; Lovejoy et al., 2000).

Although the literature associates maternal mental health problems, especially chronic maternal depression (Lovejoy et al., 2000; L. Murray et al., 2010; Parsons et al., 2012), with impairments in the mother-child interaction, contrary to the initial hypothesis, the CMD was not associated with significant impairments in the interaction. Some hypotheses may explain these results. Firstly, the common mental disorder was investigated using a screening instrument, being a less severe condition than depression. Chabrol, Bron and Le Camus (1996) also found that moderately depressed mothers presented positive interactions with their children. Furthermore, the SRQ-20 assesses not only depressive symptoms, but a variety of anxiety and somatoform symptoms, of which associations with the interaction and child development have been little investigated (Correia \& Linhares, 2007).

Consideration must be given to the fact that the majority of the mothers, despite living in poor neighborhoods, had more than eight years of study, a steady partner with employment, and a social support network. Education and social support are factors that are strongly associated with the degree of maternal sensitivity in the interaction (Shin et al., 2008). Fonseca, Silva and Otta (2010) found that when the mother had social support and emotional availability, the depressive symptoms did not interfere in the quality of the mother-infant interaction. Frizzo and Piccinini (2007), observing triadic interactions in families with and without maternal depression, found that they were not dysfunctional, possibly because the father was present and because the mothers concerned about a possible negative impact of their depression on their children, struggled to not impair the interaction, despite the suffering associated with depression.

The relationship between mental health and interaction, especially regarding the conditions at subclinical levels, still needs to be further investigated (Lovejoy et al., 2000; Parsons et al., 2012.; Tran et al., 2014). In this study, according to the initial hypothesis, the quality of the interaction was significantly related to the development of the child. Mothers of children with increased developmental risk offered less cognitive stimulation in the interactive situation, were more intrusive and unengaged and, therefore, less responsive when compared with mothers of children with normal development. The children with normal development, in turn, were more involved in the interaction.

Maternal responsiveness not only affected the overall development, but had a role in the following specific areas: language and fine motor skills. Other studies have shown that maternal responsiveness is associated with good coordination and fine motor skills (Amorim et al., 2009; Baltieri et al., 2010), is a strong predictor of receptive and expressive language (A. Murray \& Yingling, 2000) and the acquisition of social skills (Assel et al., 2002), and facilitates the formation of secure attachments (A. Murray \& Yingling, 2000; Wan \& Green, 2009).

Conversely, the mothers of children at developmental risk were more intrusive, monitoring step by step what the child did, with unnecessary interventions, comments or frequent reprimands. Possibly, by acting this way they decreased the opportunities for exploratory behavior, inhibited experimentation and prevented the child from learning from its mistakes, which would explain the developmental impairment (Adam, Gunnar, \& Tanaka, 2004).

The mothers of children with developmental risk and impairments in fine motor skills also showed low sensitivity during the interaction. In the study by Fonseca et al. (2010), high sensitivity of the mother was associated with the ability to interpret the baby and to make assumptions about their states, providing more individualized interventions and better conditions for development. Conversely, in situations where there were no adequate conditions for the caregiver to observe the subtle changes of motor behavior of the child, the children had delayed motor development (Baltieri et al., 2010).

With respect to the behavior of the children, those with normal development were more actively involved in the interactive episode, maintaining eye contact, exploring the environment, experimenting with new skills, and responding to the majority of the activities proposed by the mother. The children at risk were less involved and required the mother less. These data confirm the premise that from very early in life the child has an active role in its own acquisitions. If, in the initial interactions, the mother acts as facilitator for a significant number of developmental aspects of the child, the involvement of the child will elicit responsiveness and care from the agents with whom it interacts, allowing the caregiver to regulate her mediation and providing an environment favorable for the development (Cunha, Enumo, \& Canal, 2006; Shin et al., 2008).

Among all the interactive behaviors, low maternal cognitive stimulation was the only predictor for 
developmental risk. Piccinini et al. (2007) observed that mothers who stimulated adequately, taking advantage of the day-to-day experiences, facilitated the children's learning of skills, through their role of mediator in promoting the cognitive development of the child, helping the child to achieve desirable performance in a task that it alone would not be able to successfully perform.

According to the Theory of Structural Cognitive Modifiability, when the mother serves as an interpreter for the environmental stimulation, she makes it meaningful and relevant to the child, providing a mediated learning experience, which, in studies with older children, promoted the enrichment of the adaptive behavior repertoire, helping the child to cope efficiently with the tasks or problems of the moment, as well as future activities. It is an interactive process, in which intentionality and reciprocity between partners are indispensable (Farias, Maranhão, \& Cunha, 2008). It can be assumed that in the present study, there was intentionality when the mother focused the attention of the child on the unique attributes and perceptual qualities of objects (color, how they move, etc.) and presented activities in an organized sequence of steps. Reciprocity can be inferred from the high correlation between the behaviors of the mother and child in the interactive situation, allowing the mother to regulate her mediation from the behavior of the child in response to the presented stimulus (Cunha et al., 2006).

\section{Conclusion}

Some methodological considerations and limitations of the present study should be mentioned. First, the high percentage of children presenting developmental risk may have been influenced by the detection of false-positive cases, since the children were tested only once, by a stranger, with a screening instrument, when they were passing through the critical phase of attachment. Furthermore, due to the difficulty of interacting with strangers in this phase, the verbal performance was not observed directly, but judged from the account of the mother, which may have underestimated the communicative repertoire of the child.

The Dyadic Interaction Assessment Protocol instrument used to assess the interactions from targeted categories for the more global aspects of the interaction, showed good concordance among the observers, particularly regarding the responsiveness. However, positive affectivity of the child and disengagement of the mother, which obtained rates below .80 , need to be redefined. Since the instrument also considers the child's behavior, it allows for the active role of the child in this interaction and in its own development to be observed.

This study contributes to the comprehension of the mother-child interaction, from the beginning of life, as a process of exchange between the two agents. The results obtained support the direct relationship between the development of the child and the quality of the interaction. Children presenting developmental risk were less involved in the ludic situation and the mothers that, in turn, failed in their mediation function, were less responsive and provided less cognitive stimulation for the child. The data indicate the need to intervene in the mother/child relationship in order to avoid possible delays in child development.

\section{References}

Adam, E. K., Gunnar, M. R., \& Tanaka, A. (2004). Adult attachment, parent emotion, and observed parenting behavior: Mediator and moderator models. Child Development, 75(1), 110-122. doi:10.1111/j.1467-8624.2004.00657.x

Amorim, R. C. A., Laurentino, G. E. C., Barros, K. M. F. T., Ferreira, A. L. P. R., Moura Filho, A. G., \& Raposo, M. C. F. (2009). Programa de saúde da família: Proposta para identificação de fatores de risco para o desenvolvimento neuropsicomotor. Revista Brasileira de Fisioterapia, 13(6), 506-513. doi:10.1590/S1413-35552009005000065

Araújo, T. M., Pinho, P. S., \& Almeida, M. M. G. (2005). Prevalência de transtornos mentais comuns em mulheres e sua relação com as características sociodemográficas e o trabalho doméstico. Revista Brasileira de Saúde Materno Infantil, 5(3), 337-348.

Assel, M. A., Landry, S. H., Swank, P. R., Steelman, L., Miller-Loncar, C., \& Smith, K. E. (2002). How do mothers'childrearing histories, stress and parenting affect children's behavioral outcomes? Child: Care, Health and Development, 28(5), 359-368. doi:10.1046/j.1365-2214.2002.00285.x

Baltieri, L., Santos, D. C. C., Gibim, N. C., Souza, C. T., Batistela, A. C. T., \& Tolocka, R. E. (2010). Desempenho motor de lactentes frequentadores de berçários em creches públicas. Revista Paulista de Pediatria, 28(3), 283-289. doi:10.1590/S0103-05822010000300005

Chabrol, H., Bron, N., \& Le Camus, J. (1996). Mother-infant and father-infant interactions in postpartum depression. Infant Behavior \& Development, 19(1), 149-152. doi:10.1016/S0163-6383(96)90053-3

Correia, L. L., \& Linhares, M. B. M. (2007). Ansiedade materna nos períodos pré e pós-natal: Revisão da literatura. Revista Latino-Americana de Enfermagem, 15(4), 677-683. doi:10.1590/S0104-11692007000400024

Cunha, A. C. B., Enumo, S. R. F., \& Canal, C. P. P. (2006). Scale operationalization for analysis of maternal mediation patterns: A study with mother-child with visual impairment dyads. Revista Brasileira de Educação Especial, 12(3), 393-412. doi:10.1590/S1413-65382006000300007

Engle, P. L. (2009). Maternal mental health: Program and policy implications. The American Journal of Clinical Nutrition, 89(3), 963S-966S. doi:10.3945/ajcn.2008.26692G

Farias, I. M., Maranhão, R. V. A., \& Cunha, A. C. B. (2008). Interação professor-aluno com autismo no contexto da educação inclusiva: Análise do padrão de mediação do professor com base na teoria da Experiência de Aprendizagem Mediada (Mediated Learning Experience Theory). Revista Brasileira de Educação Especial, 14(3), 365-384. doi:10.1590/S1413-65382008000300004 
Feldman, R., \& Klein, P. S. (2003). Toddlers' self-regulated compliance to mothers, caregivers, and fathers: Implications for theories of socialization. Developmental Psychology, 39(4), 680-692. doi:10.1037/0012-1649.39.4.680

Field, T. (2010). Postpartum depression effects on early interactions, parenting, and safety practices: A review. Infant Behavior \& Development, 33(1), 1-6. doi:10.1016/j.infbeh.2009.10.005

Fonseca, V. R. J. R. M., Silva, G. A., \& Otta, E. (2010). Relação entre depressão pós-parto e disponibilidade emocional materna. Cadernos de Saúde Pública, 26(4), 738-746. doi:10.1590/S0102-311X2010000400016

Frankenburg, W. K., \& Dodds, J. B. (1967). The Denver developmental screening test. The Journal of Pediatrics, 71(2), 181-191. doi:10.1016/S0022-3476(67)80070-2

Frizzo, G. B., \& Piccinini, C. A. (2007). Depressão materna e a interaçãotriádicapai-mãe-bebê.Psicologia:Reflexãoe Crítica, 20(3), 351-360. doi:10.1590/S0102-79722007000300002

Glasheen, C., Richardson, G. A., \& Fabio, A. (2010). A systematic review of the effects of postnatal maternal anxiety on children. Archives of Women's Mental Health, 13(1), 61-74. doi:10.1007/s00737-009-0109-y

Gonçalves, D. M., Stein, A. T., \& Kapczinski, F. (2008). Avaliação de desempenho do Self-Reporting Questionnaire como instrumento de rastreamento psiquiátrico: Um estudo comparativo com o Structured Clinical Interview for DSM-IV-TR. Cadernos de Saúde Pública, 24(2), 380-390. doi:10.1590/S0102-311X2008000200017

Klein, V. C., \& Linhares, M. B. M. (2006). Prematuridade e interação mãe-criança: Revisão sistemática da literatura. Psicologia em Estudo, 11(2), 277-284. doi:10.1590/S1413-73722006000200006

Lima, M. C. P., Menezes, P. R., Carandina, L., Cesar, C. L. G., Barros, M. B.A., \& Goldbaum, M. (2008). Common mental disorders and the use of psychoactive drugs: The impact of socioeconomic conditions. Revista de Saúde Pública, 42(4), 717-723.doi:10.1590/S0034-89102008005000034

Lopes, R. C. S., Vivian, A. G., Oliveira, D. S., Deluchi, M., Tudge, J., \& Piccinini, C. A. (2012). Sentimentos maternos frente ao desenvolvimento da criança entre 24 e 28 meses. Estudos de Psicologia (Campinas), 29(Supl. 1), 737-749. doi:10.1590/S0103-166X2012000500010

Lordelo, E. R., Fonseca, A. L., \& Araújo, M. L. V. (2000). Responsividade do ambiente de desenvolvimento: Crenças e práticas como sistema cultural de criação de filhos. Psicologia: Reflexão e Crítica, 13(1), 73-80. doi:10.1590/S0102-79722000000100009

Lovejoy, M. C., Graczyk, P. A., O’Hare, E., \& Neuman, G. (2000). Maternal depression and parenting behavior: A metaanalytic review. Clinical Psychology Review, 20(5), 561-592. doi:10.1016/S0272-7358(98)00100-7
Lyra, M. C. D. P., Silva, E. C. C., \& Silva, A. C. A. (2012). Padrões de organização do sistema de comunicação mãe-bebê nas interações face a face: Estudo de cinco díades. Estudos de Psicologia (Natal),17(1), 63-71. doi:10.1590/S1413-294X2012000100008

Maragno, L., Goldbaum, M., Gianini, R. J., Novaes, H. M. D., \& César, C. L. G. (2006). Prevalência de transtornos mentais comuns em populações atendidas pelo Programa Saúde da Família (QUALIS) no Município de São Paulo, Brasil. Cadernos de Saúde Pública, 22(8), 1639-1648. doi:10.1590/S0102-311X2006000800012

Mari, J. J., \& Williams, P. (1986). A validity study of a psychiatric screening questionnaire (SRQ-20) in primary care in the city of Sao Paulo. The British Journal of Psychiatry, 148(1), 23-26. doi:10.1192/bjp.148.1.23

Murray, A. D., \& Yingling, J. L. (2000). Competence in language at 24 months: Relations with attachment security and home stimulation. The Journal of Genetic Psychology: Research and Theory on Human Development, 161(2), 133-140. doi:10.1080/00221320009596700

Murray, L., Halligan, S., \& Cooper, P. (2010).Effects of postnatal depression on mother-infant interactions and child development. In G. Bremner \& T. D. Wachs (Eds.), The Wiley-Blackwell handbook of infant development (2nd ed., Vol. 2, pp. 192-220). Chichester, England: Wiley.

Parsons, C. E., Young, K. S., Rochat, T. J., Kringelbach, M. L., \& Stein, A. (2012). Postnatal depression and its effects on child development: A review of evidence from low- and middle-income countries. British Medical Bulletin, 101(1), 57-79.doi:10.1093/bmb/ldr047

Pedromônico, M. R. M., Bragatto, E. L., \& Strobilus, R. (1999). Teste de Triagem Denver II. São Paulo, SP: UNIFESP.

Piccinini, C. A., Frizzo, G. B., \& Marin, A. H. (2007). Interações diádicas e triádicas em famílias com crianças de um ano de idade. In C. A. Piccinini \& M. L. S. Moura (Orgs.), Observando as interações pais-bebê-criança: Diferentes abordagens teóricas e metodológicas (pp. 176-211). São Paulo, SP: Casa do Psicólogo.

Pinheiro, D.P.N.(2004). Aresiliência em discussão. Psicologia em Estudo, 9(1),67-75.doi:10.1590/S1413-73722004000100009

Ribeiro, A. M., Silva, R. R. F., \& Puccini, R. F. (2010). Conhecimentos e práticas de profissionais sobre desenvolvimento da criança na atenção básica à saúde. Revista Paulista de Pediatria, 28(2), 208-214. doi:10.1590/S0103-05822010000200013

Santa Maria-Mengel, M. R. S., \& Linhares, M. B. M. (2007). Risk factors for infant developmental problems. Revista Latino-Americana de Enfermagem, 15, 837-842. doi:10.1590/S0104-11692007000700019

Seidl-de-Moura, M. L., Ribas, A. F. P., Seabra, K. C., Pessôa, L. F., Nogueira, S. E., Mendes, D. M. L. F.,... Vicente, C. C. (2008). Interações mãe-bebê de um e cinco meses: Aspectos afetivos, complexidade e sistemas parentais predominantes. Psicologia: Reflexão e Crítica, 21(1), 66-73. doi:10.1590/S0102-79722008000100009 
Shin, H., Park, Y. J., Ryu, H., \& Seomun, G. A. (2008).Maternal sensitivity: A concept analysis. Journal of Advanced Nursing, 64(3), 304-314. doi:10.1111/j.1365-2648.2008.04814.x

Silva, N. D. S. H., Lamy Filho, F., Gama, M. E. A., Lamy, Z. C., Pinheiro, A. L., \& Silva, D. N. (2011). Instrumentos de avaliação do desenvolvimento infantil de recémnascidos prematuros. Revista Brasileira de Crescimento e Desenvolvimento Humano, 21(1), 85-98.

Statistical Package for the Social Sciences (SPSS). (1997). (Version 7.5) [Programa de Computador]. Chicago: SPSS Inc.

Stein, A., Malmberg, L. E., Sylva, K., Barnes, J., \& Leach, P. (2008). The influence of maternal depression, caregiving, and socioeconomic status in the post-natal year on children's language development. Child: Care, Health and Development, 34(5), 603-612. doi:10.1111/j.1365-2214.2008.00837.x

Tran, T. D., Biggs, B.-A., Tran, T., Simpson, J. A., Mello, M. C., Hanieh, S., ... Fisher, J. (2014). Perinatal common mental disorders among women and the social and emotional development of their infants in rural Vietnam. Journal of Affective Disorders, 160, 104-112. doi:10.1016/j.jad.2013.12.034

Wan, M. W., \& Green, J. (2009). The impact of maternal psychopathology on child-mother attachment. Archives of Women's Mental Health, 12(3), 123-134. doi:10.1007/s00737-009-0066-5

Débora Gerardo Ribeiro holds a master's degree in Public Health from the Universidade Estadual Paulista "Júlio de Mesquita Filho".

Gimol Benzaquen Perosa is a Professor of the Faculdade de Medicina de Botucatu at the Universidade Estadual Paulista "Júlio de Mesquita Filho".

Flávia Helena Pereira Padovani is a Professor of the Faculdade de Medicina de Botucatu at the Universidade Estadual Paulista "Júlio de Mesquita Filho".

Received: Oct. 28, 2013

1st Revision: Apr. 9, 2014

2nd Revision: July 2, 2014

Approved: July 17, 2014

How to cite this article:

Ribeiro, D. G., Pedrosa, G. B., \& Padovani, F. H. P. (2014). Mental health, mother-child interaction and development at the end of the first year of life. Paidéia (RibeirãoPreto), 24(59), 331-339. doi: 10.1590/1982-43272459201407 


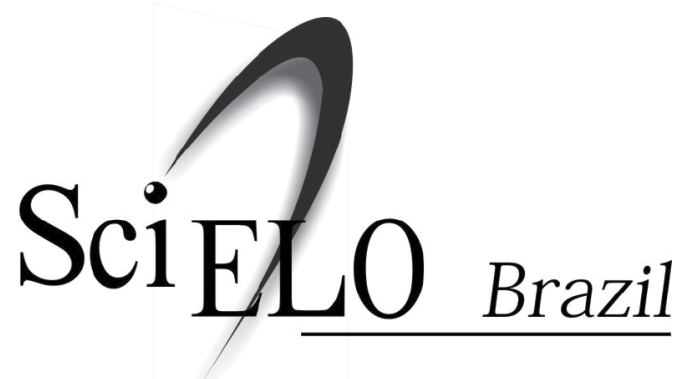

Paidéia (Ribeirão Preto) is a four-monthly publication available in full-text in the Scientific Electronic Library Online - SciELO.

The SciELO interface provides easy access to the tables of content and to the full-text articles.

The SciELO interface also provides the retrieval of articles by the author's name, the words from title, abstract and descriptors, in addition to providing bibliometric indicators and consultation indicators.

The articles are enriched with connections to the LILACS, MEDLINE and PubMed databases.

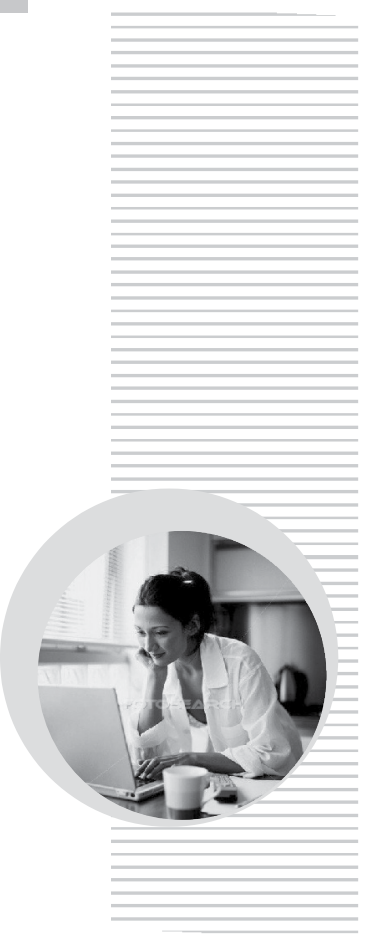

Paidéia (Ribeirão Preto) is a part of SciELO Brazil:

\section{www.scielo.br/paideia}

The SciELO interface provides access to a network of SciELO websites, gathering the major scientific journals of Latin America, Caribbean, Spain, Portugal and South Africa:

\section{www.scielo.org}

The electronic library is a project developed by the São Paulo Research Foundation (FAPESP), in partnership with the Latin American and Caribbean Center on Health Sciences Information (BIREME) and the National Council for Scientific and Technological Development (CNPq). 